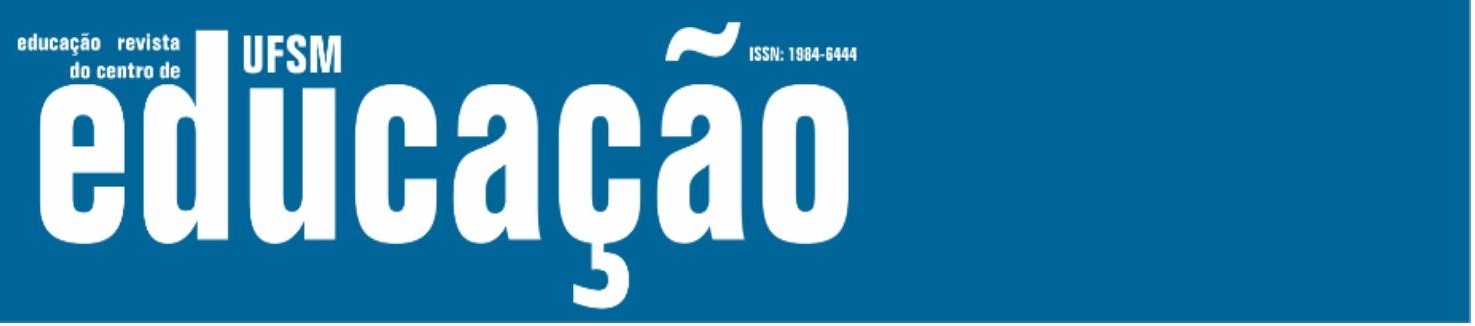

ISSN: 1984-6444 | http://dx.doi.org/10.5902/1984644441651

\title{
Interfaces entre educação profissional em alternância e formação integrada omnilateral: reflexões a partir da experiência da Escola Família Agrícola de Natalândia/MG
}

Interfaces between professional education in alternation and omnilateral integrated education: reflections from the experience of the Escola Família Agrícola of Natalândia / MG [Agricultural Family School of

Natalândia / MG] - EFAN

Daiane Aparecida Ribeiro Queiroz

Assistente Social no Instituto Federal de Educação, Ciência e Tecnologia do Norte de Minas Gerais, Arinos, Minas Gerais, Brasil

daianeufes@gmail.com - https://orcid.org/0000-0002-0630-7092

Mad'Ana Desirée Ribeiro de Castro

Professora Doutora no Instituto Federal de Educação, Ciência e Tecnologia de Goiás, Goiânia, Goiás, Brasil

mdrcastro16@gmail.com - https://orcid.org/0000-0002-0270-8251

Recebido em 07 de janeiro de 2019

Aprovado em 09 de janeiro de 2019

Publicado em 05 de maio de 2021

\section{RESUMO}

O presente trabalho tem como tema a reflexão do processo educativo do curso técnico em alternância da Escola Família Agrícola de Natalândia-MG. O objetivo aqui proposto é analisar as aproximações entre a Pedagogia da Alternância, realizada na EFAN e a formação integrada omnilateral. Trata-se de um trabalho que se desenvolve nos marcos da pesquisa qualitativa, tendo como procedimentos técnicos o estudo de caso e como instrumentos de coleta de dados a observação livre; a pesquisa documental, utilizando como fontes de coletas de dados o Projeto Político-Pedagógico e o Plano de Formação; a entrevista semiestruturada direcionada aos pais e aos professores/monitores e o grupo focal realizado com estudantes do curso técnico em agropecuária integrado ao ensino médio. Como resultado deste estudo, é possível notar que há evidenciado, nos documentos orientadores da EFAN e no processo educativo por ela desenvolvido, preocupação em desenvolver o pensamento críticoreflexivo, a criatividade e a curiosidade dos estudantes com vistas à formação integral. Além disso, observa-se o estabelecimento do vínculo entre formação geral e formação profissional, a fim de permitir que os estudantes possam se apropriar das técnicas produtivas e de seus respectivos fundamentos científicos. Neste sentido, observa-se que o modo educativo da EFAN dialoga com a perspectiva da formação integrada omnilateral.

Palavras-chave: Pedagogia da Alternância; Formação Integrada Omnilateral; EFAN. 


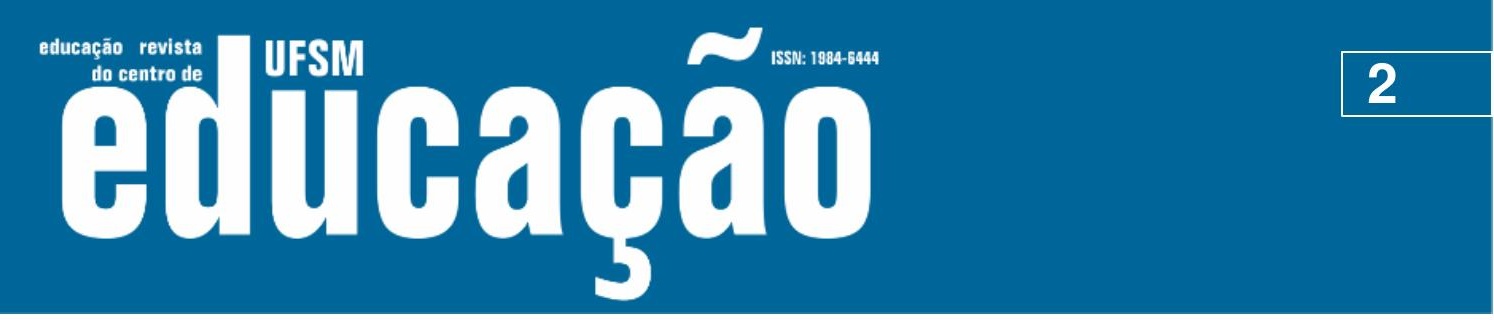

ISSN: 1984-6444 | http://dx.doi.org/10.5902/1984644441651

\section{ABSTRACT}

The present work has as its theme the reflection on the educational process of the Technical Course in Alternation of the Escola Família Agrícola de Natalândia-MG [Agricultural Family School of Natalândia / MG] - EFAN. The objective proposed here is to analyze the approximations between the Pedagogy of Alternation, conducted at EFAN, and the omnilateral integrated education. It is a work developed within the framework of qualitative research, using the case study as a technical procedure and free observation as an instrument of data collection. Also, documentary research, using as sources of data collection the Political-Pedagogical Project, the Educational Plan, the semi-structured interview directed to parents and teachers/monitors, and the focus group conducted with students from the Technical Course in Agriculture integrated with high school. As a result of this study, it is possible to perceive that there is, in the guidance documents of EFAN and about the educational process developed by it, a concern with developing critical-reflective thinking, as well as the creativity and curiosity of students with a view to integral education. Besides, it is possible to observe the establishment of a bond between general education and professional education that motivates students to take ownership of productive techniques and their respective scientific foundations. In this sense, it is observed that the educational way of EFAN dialogues with the perspective of omnilateral integrated education.

Keywords: Alternation Pedagogy; Omnilateral Integrated Training; EFAN.

\section{Introdução}

O presente escrito tem como motivação a apresentação e análise de um processo educativo que indica as possibilidades efetivas de construção da formação integrada omnilateral, buscando na Pedagogia da Alternância, enquanto princípio e prática, esta possibilidade.

Propostas pedagógicas baseadas na pedagogia da alternância têm sua origem na França, em 1935, como resultado do constructo social dos agricultores franceses na luta por uma escola diferenciada para os seus filhos, uma escola que possibilitasse aos jovens franceses permanecer no meio rural e nele ter acesso a uma educação que atendesse às necessidades específicas dessa população e que tivesse como pano de fundo o trabalho, a cultura e o modo dos trabalhadores do campo (SILVA, 2012; GIMONET, 2007).

Essa proposta educativa que teve seu limiar no sudoeste francês, expandiu-se para outras regiões da França e, no início da década de 1960, registrou-se as 


\section{Aillbapẫ

ISSN: 1984-6444 | http://dx.doi.org/10.5902/1984644441651

Essa proposta de ensino solidificou-se e expandiu-se pela França nos idos da década de 1950 e, gradativamente, chegou à Itália e a outros países europeus. Posteriormente, estabeleceu-se em outros países da Europa, África, Oceania e América do Sul.

Conforme Begnami (2003), a primeira experiência brasileira surgiu no final da década de 1960, no sul do Estado do Espírito Santo, por meio da criação da Escola Família Agrícola no município de Anchieta. Essa primeira tentativa sofreu influências daquelas desenvolvidas na Itália e contou com a atuação do Padre Humberto Pietrogrande, da Companhia de Jesus (Jesuítas), com o apoio do Movimento de Educação Promocional do Espírito Santo (MEPES). Posteriormente, já na década de 1970, expandiu-se a criação para outras regiões do Estado e, na década seguinte, ocorreu a consolidação em outras regiões do Brasil.

Chartier (1985, apud SILVA, 2003) chama a atenção de que, desde o início, estavam presentes nas MFRs as seguintes características: responsabilidade das famílias na gestão da escola por meio da criação de um conselho administrativo e de uma associação composta pelos pais e representantes locais; a vivência dos estudantes em pequenos grupos propiciada pelo regime de internato, no qual assumiam responsabilidades, inclusive pela manutenção da casa; composição de uma equipe de formadores que atuasse de acordo com as diretrizes do Conselho de Administração e a presença de uma pedagogia adaptada à realidade dos camponeses.

Em meio a essas características, Queiroz (1997) aponta as acentuadas diferenças das MFRs em relação às demais escolas rurais, uma vez que seus currículos são formulados levando em consideração a realidade do estudante e de seus familiares. Além disso, os pais são coautores no processo de formação dos filhos, pois participam de toda a vida da escola, desde o acompanhamento dos filhos, quando estão no meio familiar, até a administração, coordenação e a manutenção na escola. 
ISSN: 1984-6444 | http://dx.doi.org/10.5902/1984644441651

O "eu" no meio de "nós", engendrado por um processo educativo que reconhece a necessidade de compreender os processos histórico-sociais que permeiam a sociedade e as relações de poder que a entremeiam, possibilita formar sujeitos emancipados que refletem sobre a sua realidade, reconhecendo-a como parte de um todo. Além disso, contribui para que o estudante torna-se autônomo, atores socioprofissionais e socioculturais, "porque o processo convida a dominar a si próprio, a interagir, a assumir as dependências e a trabalhar as interdependências, mas ficando, todavia, dono de si próprio, gerindo-se e conduzindo-se" (GIMONET, 2007, p. 125).

Isso implica dizer que a alternância não se constitui como sinônimo de rotação automática entre espaços desconectados. Compreendê-la como princípio pedagógico é reconhecer que estes dois ambientes (família e escola) integram-se e não concebem a supremacia de um espaço em detrimento do outro. Isso significa

\begin{abstract}
articular universos considerados opostos ou insuficientemente interpenetrados - o mundo da escola e o mundo da vida - a teoria e a prática, o abstrato e o concreto - a alternância coloca em relação diferentes parceiros com identidades, preocupações e lógicas também diferentes: de um lado, a escola e a lógica da transmissão de saberes e, de outro, a família e a lógica da pequena produção agrícola. (SILVA, 2003, p. 12).
\end{abstract}

Nesta perspectiva, fazendo uso das acepções atribuídas por Gimonet (2007, p. 124-125), entende-se que o sentido da Pedagogia da Alternância deve ser o de "articular, distinguir sem desunir, associar sem reduzir" a vida e a escola; a formação geral e a formação profissional; os campos de saberes (da vida e dos programas escolares); os atores do processo de formação (estudantes, pais, monitores, dentre outros) e os tempos de vida do estudante, aqueles vivenciados por meio da sucessão de períodos entre o meio sociofamiliar e escola, como também a vida passada e futura.

À luz destes sentidos é possível efetivar uma proposta educativa que não se limite a alternar tempos e espaços formativos, mas cujo processo de construção do conhecimento se concretize por meio da tríade ação-reflexão-ação. 


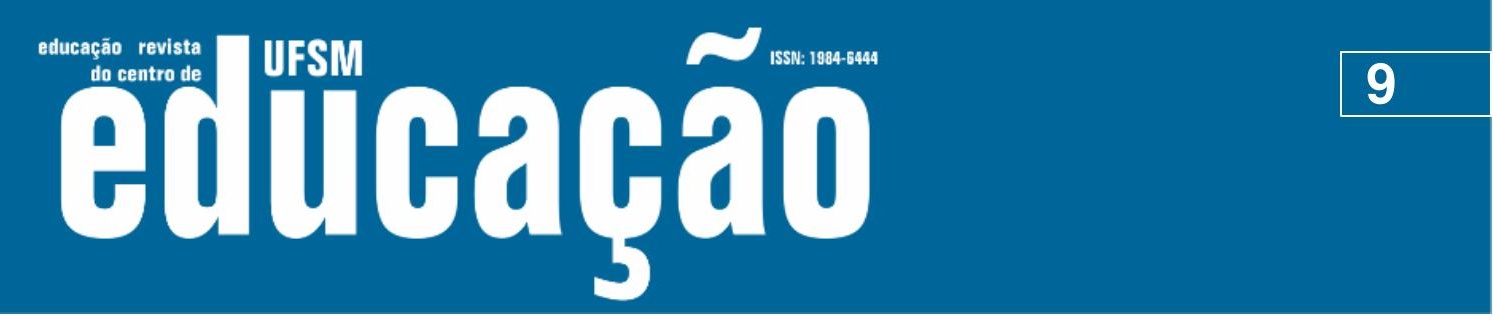

ISSN: 1984-6444 | http://dx.doi.org/10.5902/1984644441651

\section{Formação integrada omnilateral: princípios e perspectivas}

A natureza do curso ofertado na EFAN e os propósitos deste artigo indicam a necessidade, nos limites deste escrito, de discutir os princípios da formação integrada omnilateral. Estes foram inicialmente formulados por Marx e Engels como resposta ao processo histórico que instituiu a propriedade privada e a divisão do trabalho e a consequente cisão da formação dos trabalhadores no momento de consolidação do capitalismo. De forma tensionada, impulsionada pelas disputas entre projetos educativos antagônicos, a formação integrada, ou parte do que historicamente foi possível efetivar, está presente na Lei de Diretrizes e Bases (LDB), no 9.394/1996, no seu Art. 36 C, e no processo educativo da Rede Federal de Educação Profissional e Tecnológica, amparado pela Lei no 11.892/2008, no item I do Art.7º, por exemplo.

Segundo Manacorda (2007), Marx e Engels indicam a necessidade de que instrução e trabalho (como articulação entre teoria e prática) estejam vinculados; referindo-se à sociedade comunista, na qual a propriedade privada e a divisão de trabalho estarão superados e as necessidades de todos supridas, os homens novos deverão desenvolver suas aptidões em todos os sentidos, ou seja, de maneira omnilateral, rompendo assim com a formação unilateral e, com ela, seus aspectos alienantes. Chamaram atenção ainda para que os estudantes tivessem acesso aos fundamentos científicos gerais de todos os processos da produção e que pudessem fazer uso prático e manejo dos instrumentos elementares de todos os ofícios.

No exposto acima, apreende-se que formação integrada omnilateral é resposta a uma situação formativa histórica que perdura nos dias atuais. O propósito fundante é a busca pela formação de todas as potencialidades do homem. Neste processo, é importante efetivar uma educação que se assente na relação entre teoria e prática e na apreensão dos fundamentos científicos e tecnológicos dos processos produtivos e da apropriação dos instrumentos e seus manejos na produção. A finalidade para Marx e Engels, em relação à instrução, é a realização da liberdade. Portanto, a formação omnilateral compreende 


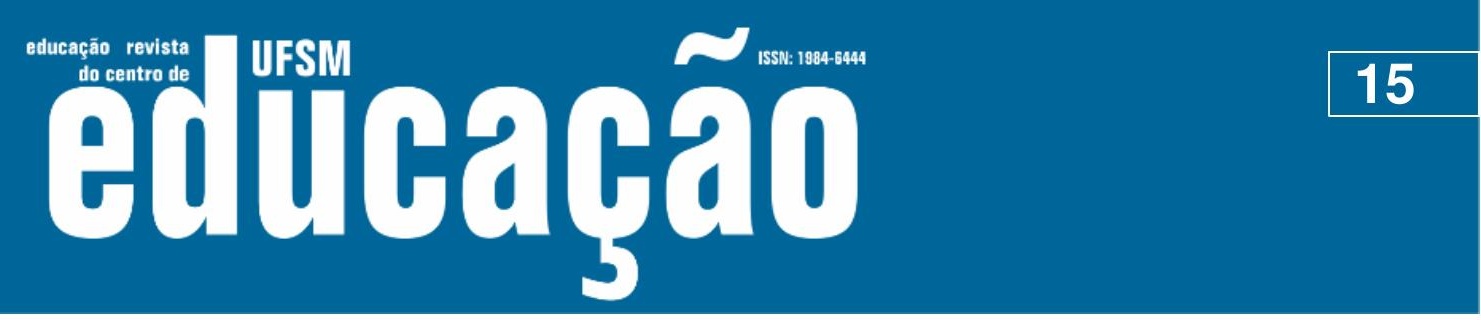

ISSN: 1984-6444 | http://dx.doi.org/10.5902/1984644441651

Proporcionar a apropriação de conhecimentos - da ciência, tecnologia, da cultura e do trabalho - envolvidos de forma indissociável na atuação enquanto Técnicos em Agropecuária e cidadãos;

Realizar a integração dos conhecimentos científicos, culturais, técnicos e tecnológicos;

Proporcionar a compreensão do significado da ciência, das linguagens contemporâneas e das transformações históricas, sociais e culturais pelas quais passaram a sociedade.

O documento postula também o vínculo entre processo formativo com a realidade dos estudantes. Esta relação é, para a Pedagogia da Alternância, o fundamento que tem possibilitado aos estudantes do campo a permanência na escola e a continuidade e melhoramento do seu trabalho no campo junto às famílias. Este vínculo, mais que uma estratégia didática, assume caráter orgânico, ou seja, de produção da vida, que, neste caso, se dá na relação entre escola e família, entre educação e trabalho, entre reino da necessidade e reino da liberdade. Esta perspectiva posta pela Pedagogia da Alternância vai ao encontro dos princípios da omnilateralidade, pois requer que os processos formativos considerem o contexto histórico para desenvolver-se (ARAÚJO; FRIGOTTO, 2015; BARBOSA, 2017). Caso contrário, conhecimentos e métodos pedagógicos se tornam "ocos", acentuadamente formais e alheios às demandas sociais.

Outra premissa da formação integrada omnilateral é a proposição de situações formativas que instiguem a constituição de sujeitos que combinem formação teóricoprática e consciência ético-política (ARAÚJO; FRIGOTTO, 2015; BARBOSA, 2007; RAMOS, 2007). Preocupação também evidenciada pelo PPP quando objetiva "oferecer aos educandos uma formação mais completa, de caráter integral para a leitura do mundo e atuação como cidadão pertencente à sua Comunidade, seu município, estado e país, integrado dignamente a sua sociedade política" (ESCOLA FAMÍLIA AGRÍCOLA DE NATALÂNDIA, 2018, p. 8).

Baseando-se nos objetivos traçados no mencionado documento, é possível perceber, portanto, que o horizonte para o qual aponta o processo formativo da EFAN alicerça-se na perspectiva de uma formação dos sujeitos em suas múltiplas dimensões, em sua totalidade, omnilateralidade, uma vez que assume o compromisso com a formação integral dos estudantes e não apenas com a oferta de um curso que 


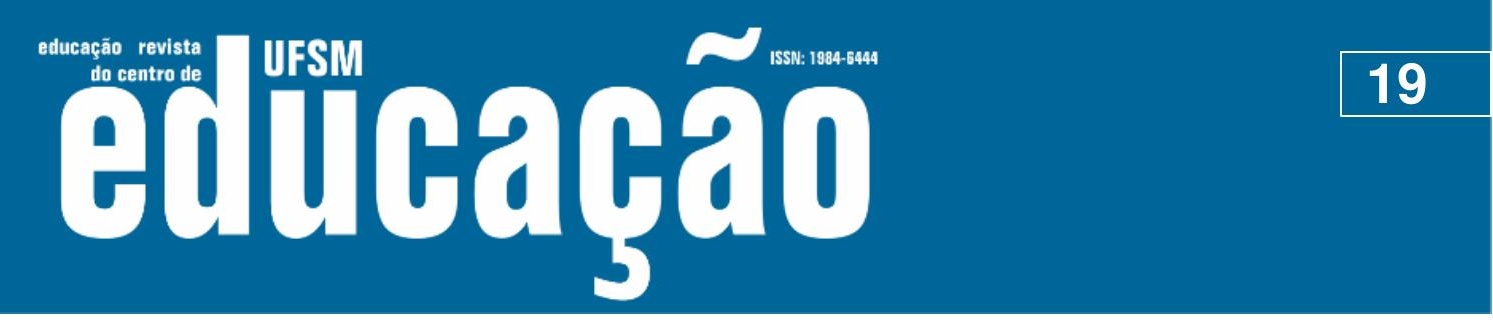

ISSN: 1984-6444 | http://dx.doi.org/10.5902/1984644441651

[...] na colocação em comum ${ }^{5}$, né? Que é o momento em que o aluno vai trazer aquelas informações do Plano de Estudo e socializar, né. [...] é importante também porque nós acabamos verificando que há diversas expressões culturais, diversas formas de se fazer uma coisa, né. Imagina que nós estamos aqui, Riachinho, Urucuia estão muito próximo, né? E se você for pegar a forma como se faz uma cerca em Natalândia é totalmente da forma como se faz uma cerca em Riachinho, em Buritis, em João Pinheiro, né? É diferente. Cada região, [...] tem um comportamento diferente [...] até a forma de conversar particular. [...] eles passam a entender que cada região tem uma cultura diferente [...] (MONITOR 1).

Sobre a questão cultural, o Monitor 3 faz um relato significativo:

[...] nós chamamos várias expressões culturais para dentro da instituição de ensino, onde os alunos vão vivenciar isso, né? Coisas que não são muito normais para essa nossa região, né? A gente pega culturas afrodescendentes, né? E não apenas assim, encenação apenas, pessoas que vivem daquilo, né? Que aquilo é rotina, é vida delas e traz para dentro da escola, acho que o menino tem ampliação da sua visão de mundo.

As expressões culturais não são tratadas como folclore, como algo exótico. Há a necessidade de superar o folclore como premissa para desenvolver uma formação ético-política (GRAMSCI, 1995). É significativo que haja interação com aqueles que demonstram que a cultura é um modo de ser dos grupos, da sua visão de mundo e da forma como organizam-se para estar no mundo. Não é um fenômeno estático, vazio de conteúdo humano. Ao contrário, expressam a diversidade de respostas que os homens dão para a reprodução da vida, em suas muitas necessidades e dimensões.

Outro princípio importante da formação integrada omnilateral é o estabelecimento do vínculo entre a formação geral e a formação profissional e, neste mesmo processo, a integração entre formações distintas, a fim de que se possa permitir que os estudantes apropriem-se de conhecimentos que permitam a sua inserção na vida produtiva dignamente, conforme destaca Ramos (2007). Essa é a natureza do Curso Técnico em Agropecuária. Deste modo, integrar não se limita a uma simples descrição nos documentos institucionais ou a uma junção entre disciplinas que contemplam a formação técnica e a formação geral. Isso porque a integração se externa no processo educativo da EFAN, conforme destacado nas falas que se seguem: 


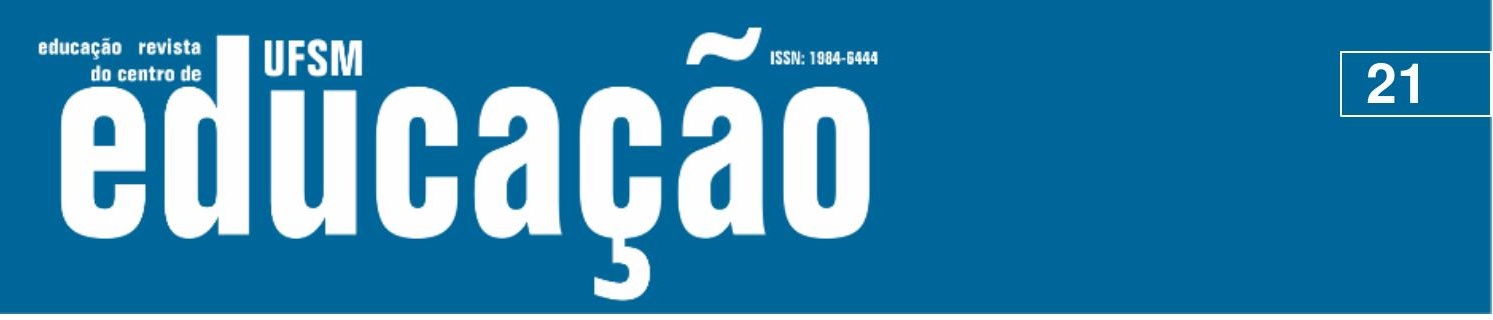

ISSN: 1984-6444 | http://dx.doi.org/10.5902/1984644441651

deem prosseguimento aos estudos, ingressando em cursos superiores de muitas universidades públicas.

É de sempre ofertar para o menino um ensino crítico, acima de tudo, tanto é que os meninos criticam até demais, às vezes, né? E a gente, claro, sempre tenta colocar na mente deles que para criticarem, tudo que você criticar sempre apresentar uma solução, não só criticar por criticar, né? [...] Nós queremos que os nossos alunos eles consigam cada vez mais adentrarem em universidades públicas né? e assim é o sonho de todo pai, né? É o sonho de toda mãe, é o sonho do menino que ele passe a ter as vezes aqui dentro, porque ele vem pra cá não com essa perspectiva e, claro, se ele não quiser, ele tem o curso técnico, vai gerenciar a propriedade da família, vai obter uma renda, talvez até superior a de quem faz a graduação, né? (MONITOR 1).

Olha, assim, a avaliação dos alunos eu acho muito que é bem diferenciada [...] assim, a avaliação, a formação diferenciada de qualidade, né, de muitas oportunidades também, né, uma vez que o aluno conclui ou estuda aqui eles têm várias oportunidades de entrar na Universidade, de entrar, fazer outros cursos, e na formação, a questão, a formação ética, a questão da formação cidadã [...] (MONITOR 3).

Araújo e Frigotto (2015) e Barbosa (2017) destacam que os procedimentos pedagógicos (didáticos) para a efetivação da formação omnilateral necessitam criar situações que instiguem o pensamento crítico-reflexivo, a curiosidade, a criatividade, importantes aspectos para a constituição da autonomia dos estudantes. Nesse sentido, o processo educativo efetivado na EFAN tem se preocupado com estes procedimentos.

Bom, a colocação em comum, basicamente, reúne os quatro tutores dos alunos, é...em sala de aula. Aí tipo, o meu tutor leva a questão, eu respondo. Aí já vem outra pessoa de outro grupo já responde e vai debatendo, né, dentro da sala de aula. Mesma questão é respondida por quase todos os alunos da sala. Tipo, minha resposta, eu falo uma resposta, ela não tá completa totalmente. Aí outra pessoa vai e responde, aí assim responde todo o tema (ADOLESCENTE 6).

É, a colocação em comum aqui é... mais ainda pode ser considerada como uma troca de saberes, é porque você chega com seu artigo pronto, seu trabalho pronto, você vai na frente apresenta juntamente com seus, mais uns quatro, cinco alunos e vocês vão lá e discutem sobre esse, esse tal tema. $O$ resto da sala, eles fazem pergunta pra você e enquanto você explica o que você entendeu, você mesmo tira suas dúvidas com as perguntas deles (Adolescente 4).

Os documentos institucionais e o expresso pelos sujeitos desta pesquisa acerca do processo educativo do curso técnico em alternância da EFAN indicam que há um trabalho de "edificação" de um novo homem, diferente do que se apresenta hegemonicamente atualmente. Há aproximações entre este processo e a 


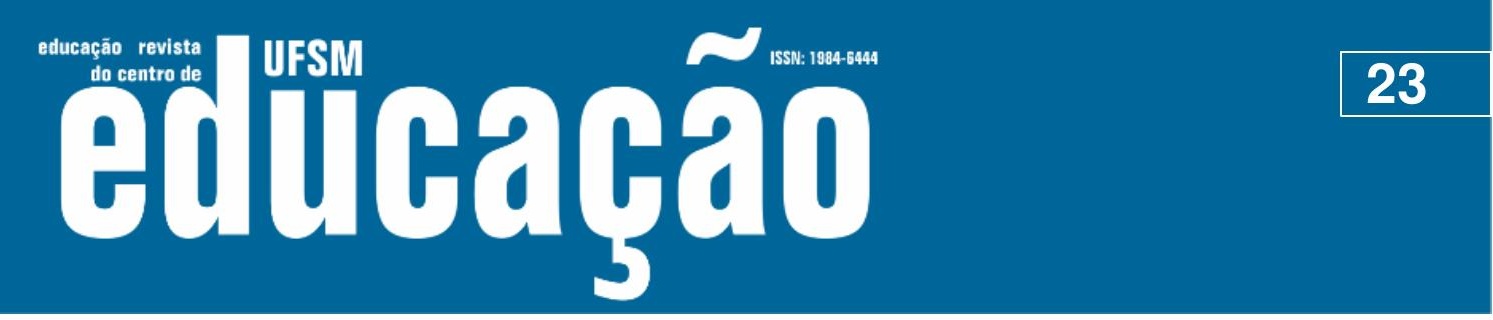

ISSN: 1984-6444 | http://dx.doi.org/10.5902/1984644441651

estão aí hoje fortemente vinculadas às demandas da reprodução do capital. Até então, essas manifestavam-se na educação profissional, mas, hoje, com a pedagogia das competências, está posta desde a educação infantil.

Estudar, pesquisar e socializar experiências que colocam proposituras e processos contra-hegemônicos, afirmando e realizando uma escola que, como ensina os princípios da formação omnilateral, não fique refém de processos educativos que repõem a fragmentação do homem, a sua consciência e seu exercício político, se colocam como forma de resistência e de desvelar que é possível construir uma outra educação, que reintegre o homem, apesar de tantas desintegrações.

\section{Referências}

ARAÚJO, Ronaldo Marcos de Lima; FRIGOTTO, Gaudêncio. Práticas pedagógicas e ensino integrado. Educação em Questão, Natal, v. 52, n. 38, p. 61-80, mai./ago. 2015. Disponível em: https://periodicos.ufrn.br/educacaoemquestao/article/view/7956 Acesso em: 04 nov. 2020.

BARBOSA, Sebastião Cláudio. A formação integrada omnilateral: fundamentos e práticas no Instituto Federal de Goiás a partir do Proeja. 2017. 202 f. (Tese de Doutorado) - Faculdade de Educação, Universidade Federal de Goiás, Goiânia, 2017.

BEGNAMI, João Batista. Formação pedagógica de monitores das escolas famílias agrícolas e alternâncias: um estudo intensivo dos processos formativos de cinco monitores. 2003. 319f. Dissertação (Mestrado Internacional em Ciências da Educação). Universidade Nova de Lisboa-Portugal - Universidade François Rabelais de Tours, França, 2003.

CERQUEIRA, Márcia Cristiana de Almeida; SANTOS, Célia Regina Batista dos. As Escolas Famílias Agrícolas, a Pedagogia da Alternância e o Caderno da Realidade.

Disponível

em http://coral.ufsm.br/sifedocregional/images/Anais/Eixo\%2004/Marcia\%20Cristina\%20 de\%20A.\%20Cerqueira\%20e\%20C\%C3\%A9lia\%20Regina\%20B.\%20dos\%20Santo s.pdf. Acesso em: 15 maio 2019.

CIAVATTA, Maria. A formação integrada: a escola e o trabalho como lugares da memória e de identidade. In: FRIGOTTO, G.; CIAVATTA, M.; RAMOS, M. (Org.). Ensino Médio Integrado: concepções e contradições. São Paulo: Cortez, 2012. p. 83-106.

ESCOLA FAMÍLIA AGRíCOLA DE NATALÂNDIA. Plano de Formação. 2015. Disponível em https://noticias.efanmg.com/documentos-importantes/. Acesso em: 10 set. 2018. 


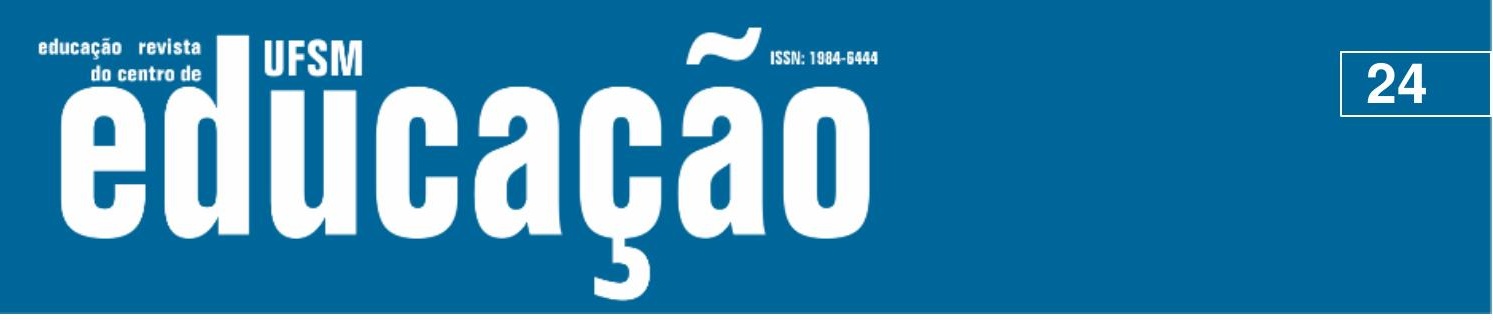

ISSN: 1984-6444 | http://dx.doi.org/10.5902/1984644441651

ESCOLA FAMÍlIA AGRÍCOLA DE NATALÂNDIA. Projeto Político-Pedagógico. 2018. Disponível em https://noticias.efanmg.com/documentos-importantes/. Acesso em: 10 set. 2018.

FRIGOTTO, Gaudêncio. Concepções mudanças no mundo do trabalho e o ensino médio. Disponível em: http://www.ia.ufrrj.br/ppgea/conteudo/conteudo-20082/Educacao-MII/2SF/2-Frigotto2008.pdf. Acesso em: 10 nov. 2020.

GIMONET, Jean-Claude. Praticar e compreender a Pedagogia da Alternância dos CEFFAs. Petrópolis: Vozes, 2007.

GRAMSCI, Antônio. Os intelectuais e a organização da cultura. Rio de Janeiro, Civilização Brasileira, 1995.

MANACORDA, Mario Alighiero. Marx e a pedagogia moderna. São Paulo: Alínea, 2007.

NASCIMENTO, Claudemiro Godoy. Pedagogia da resistência cultural: Um pensar a educação a partir da realidade campesina. In: Encontro Regional de Geografia (EREGEO), VIII, 2003, Cidade de Goiás. Anais.... Disponível em: http://www.geocities.ws/claugnas/pedagogiaresistencia.doc. Acesso em: 10 nov. 2020.

QUEIROZ, João Batista Pereira de. Educação rural no Brasil e EFAS: o processo de implantação da Escola Família Agrícola (EFA) de Goiás. 1997. Dissertação (Mestrado em Educação) - MEB- Faculdade de Educação, Universidade Federal de Goiás, Goiânia, 1997.

RAMOS, Marise Nogueira. Concepção do ensino médio integrado à formação profissional. Seminário sobre Ensino Médio, Superintendência de Ensino Médio da Secretaria de Educação do Estado do Rio Grande do Norte, Natal, agosto de 2007. (mimeo).

ROCHA, Isabel Xavier de Oliveira. A formação integral nos CEFFAs. Revista Formação por Alternância, Brasília, v. 1, p. 05-18, 2007.

SAVIANI, Demerval. O choque teórico da politecnia. Trabalho, Educação e Saúde, Rio de Janeiro, v. 1, n. 1, p. 131-152, Mar. 2003. Disponível em http://www.scielo.br/scielo.php?script=sci_arttext\&pid=S1981-77462003000100010.

Acesso em: 20 de mar. 2019.

SILVA, Lourdes Helena da. Experiências de formação de jovens do campo: alternância ou alternância? Viçosa: UFV, 2003.

SILVA, Lourdes Helena da. Educação Rural em Minas Gerais: origens, concepções e trajetória da pedagogia da alternância das EFA's. Revista Educação em Perspectiva, Viçosa, v. 3, n. 1, p. 105-125, 2012. 


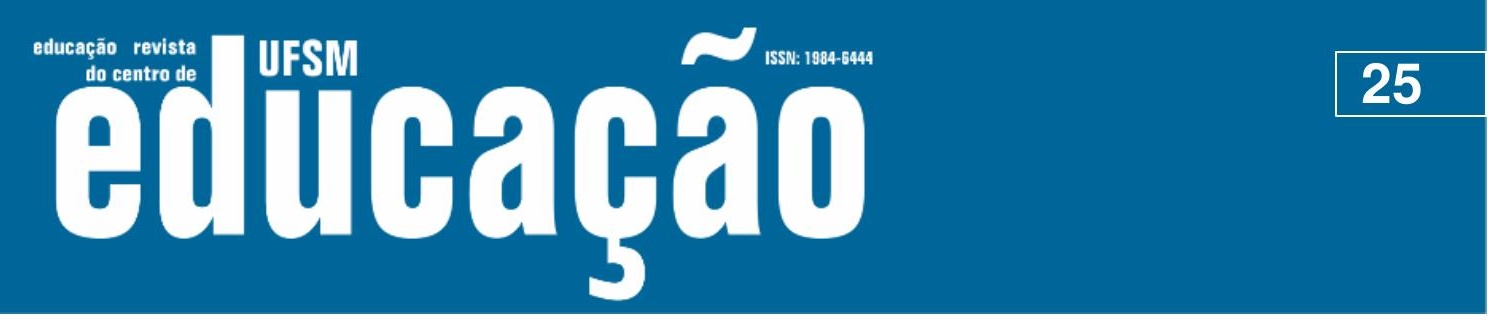

ISSN: 1984-6444 | http://dx.doi.org/10.5902/1984644441651

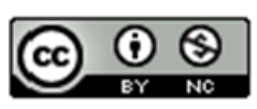

This work is licensed under a Creative Commons Attribution-NonCommercial 4.0 International (CC BY-NC 4.0)

\title{
Notas
}

\begin{abstract}
${ }^{1}$ Nesta pesquisa, faz-se uso da distinção entre professor e professor/monitor. Neste caso, professores são os profissionais contratados para ministrar aulas de determinada disciplina, restringindo suas atividades à sala de aula. Por sua vez, os monitores também são professores, contudo, além dessa atividade, são os responsáveis pelo acompanhamento diário dos estudantes no ambiente escolar e no meio sociofamiliar. Como se trata de uma escola em tempo integral, geralmente os monitores moram nas dependências da escola ou passam a maior parte da semana no ambiente escolar. Segundo Cerqueira e Santos (2012, p. 8), no Plano de Estudo, os professores/monitores "agem como motivadores, orientadores e facilitadores desse processo de aprendizagem e capacitação. Além disso, o monitor deve visitar as famílias e as comunidades dos alunos a fim de efetivarem um real acompanhamento destes alunos no seu período de alternância".
\end{abstract}

2 Em relação aos pais, a ideia inicial seria entrevistar 15 pais, contudo, foram realizadas 11 entrevistas considerando aqueles que, durante a reunião ocorrida na EFAN, em 03/02/2019, manifestaram interesse em participar da pesquisa. Por sua vez, para a realização do grupo focal com os estudantes, foi definido o número de 15 participantes, a fim de permitir a efetiva participação dos participantes, sendo que a escolha foi realizada a partir daqueles que assentiram em participar com autorização dos pais e/ou responsáveis. Por fim, foram entrevistados os três monitores responsáveis por conduzir o Plano de Estudos na turma cuja observação livre se efetivou.

3 Gimonet (2007) destaca que para que uma escola seja qualificada como alternada não basta ter alguma relação com a área profissional, tampouco empregar a sucessão de tempos e espaços formativos sem nenhuma vinculação entre si. Há, segundo o autor, verdadeiras e falsas alternâncias, a saber: a) falsa alternância ou justaposta: compreendida pela sucessão dos tempos ou períodos destinados ao trabalho e ao estudo, sem que haja uma relação entre eles. b) alternância aproximativa se caracteriza pela organização didática dos dois tempos de formação, contudo, sem que se efetive uma verdadeira interação entre eles. c) alternância real ou integrativa: compreende a sucessão dos tempos de formação teórica e prática como uma unidade de tempos formativos.

4 Entende-se por ontocriativo a condição que permite ao ser social compreender a realidade, transformá-la e, ao mesmo tempo, transformar a si mesmo (FRIGOTTO, 2008).

${ }^{5}$ Os temas são abordados no Plano de Estudo, procedimento pedagógico da Pedagogia da Alternância que é construído pela família, professores e estudantes e tem como objetivo tratar de temas de estudo de interesse destes segmentos. 